Maksymilian Drozdowicz (D) Ostravská univerzita $v$ Ostravě maksymilian.drozdowicz@osu.cz

\title{
Ernesto Cardenal y Francisco La iglesia como objeto de análisis poético-teológico
}

\section{Resumen:}

El Papa Francisco y el poeta nicaragüense Ernesto Cardenal coinciden en muchos aspectos al interpretar la teología de la comunidad. Cardenal, un representante de la Teología de la Liberación, y el Papa Francisco, que va al encuentro de dicha teología, son dos personajes característicos del pensamiento latinoamericano. En Ernesto Cardenal, autor de Cántico cósmico y el Papa actual, autor de encíclicas que tocan el tema de la Iglesia como comunidad, se pueden encontrar puntos en común. En el presente estudio se va a proseguir con la característica del cántico y de la encíclica como dos géneros y herramientas para describir la realidad eclesial, para profundizar en la visión de la Iglesia como comunidad de los pobres y necesitados. La de Francisco y Cardenal, son posturas similares pero la ortodoxia del Pontífice exige algo más de lo que propone el poeta-sacerdote rebelde de Nicaragua.

Palabras clave: Papa Francisco, Ernesto Cardenal, Teología de la Liberación, Iglesia católica, encíclica

\section{Abstract: \\ Ernesto Cardenal and Francis. The Church as an Objective of Poetic and Theological Analysis \\ The views of Pope Francis and the Nicaraguan poet Ernesto Cardenal converge in many aspects when interpreting the theology of the community. Cardenal, the}


representative of the Liberation Theology, and Pope Francis, who heads toward the mentioned theology, are the two personalities of the Latin American thought. Cardenal, the author of Cántico cósmico, and the current Pope, the author of the encyclicals on the topic of the Church as a community, can find some common points. This study will continue with the characteristics of the canticle and encyclical as the two genres and means of description of the ecclesiastical reality. Furthermore, the study will focus on the deepening of the vision of the Church as a community of the poor and needy. The attitudes of Francis and Cardenal are similar, but the orthodoxy of the Sovereign Pontiff requires even more than the rebellious poet-priest from Nicaragua proposes.

Key words: Pope Francis, Ernesto Cardenal, liberation theology, catholic Church, encyclical

\section{Doctrina}

Las fuentes de la teología católica están siendo estudiadas con más rigor a partir del siglo XIV, a partir del español Melchor Cano (15091560), cuya obra De locis theologicis (1563) marca la cumbre de la metodología teológica, desarrollada y perfeccionada luego por el Concilio Vaticano II que ha establecido seis categorías conductoras de la eclesiología: pueblo de Dios, templo del Espíritu Santo, casa de Dios, communio, sacramento y Cuerpo Místico de Cristo. Con el ingrediente personalista de Juan Pablo II, la Iglesia católica se considera cristocéntrica, ya que solamente Jesús trae al hombre una verdadera libertad (Napiórkowski, 2011: 39, 13). Con el Papa Francisco, a partir de 2013, ocurre el cambio de acentos en la eclesiología. La Iglesia ya empieza a apuntar a la humanidad herida. Para Francisco, la Iglesia es como un hospital de sangre, donde hay heridos a quienes se busca en las periferias de la sociedad. La Iglesia de Francisco ya no se conforma con la feligresía que llega obedientemente a los templos cada domingo (Bargielska, 2016: 17) - es sobre todo misionera y de salida. Así lo asegura el Papa en la exhortación apostólica Evangelii gaudium (EG): "[...] no podemos quedarnos tranquilos en espera pasiva en nuestros templos" $(E G, 15)$. En Cracovia, en la Jornada Mundial de la Juventud, 
en 2016, el Papa subrayó la verdad sobre la Iglesia-Madre "siempre atenta", que se empeña en que sus hijos vivan "una conversión que les devuelva la alegría de la fe y el deseo de comprometerse con el Evangelio" $(E G, 14)$.

Repetidas veces en las enseñanzas de Francisco aparece el concepto de vicinanza en el sentido de 'estar cerca', 'el salir al encuentro con los demás', 'el toque', así como se toca un cuerpo sufriente (Sporniak, 2016: 23). De ahí viene la novedad que consiste en descentralizar la Iglesia (cfr. $E G, 16$ ). Es vital, recuerda el Pontífice, "que hoy la Iglesia salga a anunciar el Evangelio a todos, en todos los lugares, en todas las ocasiones, sin demoras, sin asco y sin miedo. La alegría del Evangelio es para todo el pueblo, no puede excluir a nadie" $(E G, 23)$. Es necesario un cambio radical porque la Ecclesia "no es una aduana, es la casa paterna donde hay lugar para cada uno con su vida a cuestas" $(E G, 47)$. Al salir afuera, esta Iglesia se ensucia y mancha, pero más vale arriesgar que quedarse en sus seguridades $(E G, 49)$. También Francisco pide: "No quiero una Iglesia preocupada por ser el centro y que termine clausurada en una maraña de obsesiones y procedimientos" $(E G, 74)$, sino que ella se abra, sin centrarse en una sola nación o raza, porque eso conduce a fanatismos $(E G, 117)$.

\section{Bartolomé de las Casas y su "escuela"}

Los pobres para el Papa Francisco, del mismo modo que los indios para fray Bartolomé de las Casas, son las personas más importantes de la Iglesia: "Hay que decir sin vueltas que existe un vínculo inseparable entre nuestra fe y los pobres. Nunca los dejemos solos", dice Francisco $(E G, 48)$. El Pontífice argentino desarrolla este deseo al pedir aún más: "una Iglesia pobre para los pobres", quienes "tienen mucho que enseñarnos", porque ellos "en sus propios dolores conocen al Cristo sufriente". Por eso es necesario que evangelicen a toda la Iglesia, que se pongan "en el centro del camino de la Iglesia" $(E G, 198)$. El obispo de Chiapas, a raíz de la crítica hecha por Montesinos y a consecuencia de una lectura atenta de un fragmento de la Biblia (concretamente Eclo 24, 18-22), descubre una mutua y estrecha relación entre los 
conceptos: 'pobre', 'pan', 'sacrificio eucarístico' y 'libertad' (Dussel, 1983, 18-27). Fray Bartolomé, al rezar en el ofertorio de la misa: "Bendito seas, Señor, Dios del Universo, por este pan, fruto de la tierra y del trabajo del hombre, que recibimos", se da cuenta que no quedan lejos estos tres elementos: trabajo, tierra (naturaleza) y pan (fruto). Y como Jesús "se despojó tomando la condición de servidor" (Flp 2, 6-7), hay que demostrar el valor del esclavo como hombre que trabaja. Dussel advierte que el esclavo-siervo (hebed) en hebreo significa 'hombre que trabaja'. Tomando a Bartolomé por modelo, la Iglesia debe practicar la justicia, ya que es ella la prometida para los anawim bíblicos: pobres, trabajadores y desamparados. En conclusión:

La justicia es el negar la negación del pecado. Lo que el pecado ha asesinado la justicia lo resucita, le da de nuevo vida. El pecado roba el producto del trabajo. La justicia restituye el fruto del trabajo: niega al robo, afirma al desposeído, al pobre. (Dussel, 1983: 24)

El poeta nicaragüense Ernesto Cardenal toma en su poesía el ejemplo del gran dominico. Con su propio ejemplo, al fundar la comunidad en el archipiélago de Solentiname, parece imitar al obispo de Chiapas, evocado también en su poesía, por ejemplo en "Cantiga 15": "Y quiso [Bartolomé de las Casas] fundar una comunidad de paz al sur del lago / (por Solentiname) [...]" (Cardenal, 2012a: 116). Varias veces las Casas es presentado como profeta, un modelo de vida, el que atrae a los indígenas. El poeta deja constancia de eso en "Cantiga 38": "Hasta que Las Casas dijera (Las Casas creo) / «Todas las naciones del mundo son hombres»" (Cardenal, 2012a: 340). El poeta expresa su aprecio por este personaje en otras aseveraciones:

Repicaron las campanas de alboroto con las Leyes Nuevas.

$\mathrm{Y}$ unos se entristecían.

maldecían a Fray Bartolomé de Las Casas.

Sin hombre no hay mundo

dijo al antropólogo el campesino chileno.

(Cardenal, 2012a: 197) 
Para Cardenal, el continuador del gran dominico es cualquier mártir caído en la lucha contra las injusticias; el que, muchas veces, debe combatir como guerrillero. El poeta piensa en centenares de desconocidos, sin nombre, pero reconociendo también a otras figuras conocidas como San Óscar Arnulfo Romero ("San Monseñor Romero" - Cardenal, 2012a: 197), obispo de San Salvador, beatificado en 2015 y canonizado en 2018 por el Papa Francisco. Cardenal lo "canoniza" antes, lo trata como a un santo. También al grupo de estos luchadores incansables pertenece el obispo Pedro Casaldáliga (ibidem) o el padre Gaspar García Laviana: "Por eso el español García Laviana se quitó la sotana / y se metió al Frente, y murió combatiendo" (Cardenal, 2012a: 231).

Otro combatiente lascasiano sería el presbítero y guerrillero colombiano Camilo Torres. De él -como de un buen hombre de la Iglesia-se deja constancia en Las ínsulas extrañas (2002):

Él había sacrificado el poder celebrar la eucaristía para crear las condiciones que la hicieran más auténtica. El sacrificio de la misma no podía ser válido si antes no se realiza el amor al prójimo. [...]. Una cosa novedosa en Camilo es que llamaba a la unión de marxistas y cristianos para luchar por la revolución. No estar discutiendo si Dios existe, cuando sabemos que la miseria existe. (Cardenal, 2002: 66)

Viene a la memoria la figura del padre Camilo Torres descrito poéticamente en Cántico cósmico:

Comunión...

RECUERDO DE MI PRIMERA COMUNIÓN

*Camilo Torres Restrepo*

(con su camisita marinera)

Como lo teníamos enmarcado en nuestra isla de Solentiname.

Adonde había llegado como solitario coco.

Tu sangre vino para todos

tu cuerpo pan para todos.

(Cardenal, 2012a: 157) 
Para Cardenal, al grupo de los que supieron "dejar sus ritos y ver los problemas del pueblo" (Cardenal, 2002: 328) pertenecen, también mencionados en Cántico cósmico, el trapense norteamericano Thomas Merton, el teólogo chileno Segundo Galilea, el padre marxista chileno Raúl Blanquart, el padre norteamericano Daniel Berrigan, la fundadora de Catholic Worker Dorothy Day, los sacerdotes-obreros y varios otros activistas en el campo teológico-social, incluido el poeta y ex-seminarista nicaragüense Leonel Rugama y, por supuesto, el mismo Ernesto 'Che' Guevara.

Cardenal, defensor del pobre al igual que Bartolomé de las Casas, se declara partidario del Papa Francisco: "Siempre he estado dentro de la Iglesia. Siempre sigo estándolo y ahora con más gusto con el Papa Francisco" ("Francisco es mejor...", 2016). Confiesa incluso que el Papa Francisco lo ha conquistado y que con él llegó al Vaticano "la verdadera revolución". En las entrevistas Cardenal siempre dice sentirse identificado con este Papa por las siguientes razones:

Es un Papa que no quiere actuar como Papa, por eso ha escogido el título de obispo de Roma. No ha querido vivir en el Palacio Pontificio. [...]. Está haciendo una verdadera revolución en el Vaticano, y eso es una revolución en la Iglesia y una revolución en el mundo. ("Francisco es mejor...", 2016)

El nicaragüense le considera a Francisco como un político atrevido: "[...] el Evangelio [...] es un mensaje político, que es cambiar el mundo para que haya un mundo mejor después de 100 mil años de desigualdad" ("Ernesto Cardenal: «Francisco...»", 2014) y dice aplaudir los pasos del Papa Francisco, muy distinto de los dos "funestos" pontífices anteriores (González Harbour, 2015). El actual Papa elige la pobreza como el camino propicio de testimonio de la Iglesia. Cardenal lo ve del mismo modo, declarando su amistad con el obispo Pedro Casaldáliga de la Amazonia, quien dijo: "Mientras haya pobres, habrá teología de la liberación" (Cardenal, 2015). En este sentido, y partiendo de esta afirmación, se debe considerar a Francisco y a Cardenal como dos promotores en la búsqueda de soluciones teológicas para el escándalo de la pobreza. 
Según consta en la carta encíclica Lumen fidei $(L F)$ del Papa Francisco, la Iglesia une a los creyentes y los conduce por los caminos de la fe (LF, 38), ya que la unidad de la Iglesia significa la unidad de la fe $(L F, 47)^{1}$. Al pedir en la encíclica Laudato sì $(L S)$ la unidad de los miembros de la Iglesia, el Papa Francisco no pierde de vista a los pobres (cfr. $L S, 7$ ), evocando la voz de los obispos paraguayos:

Todo campesino tiene derecho natural a poseer un lote racional de tierra donde pueda establecer su hogar, trabajar para la subsistencia de su familia y tener seguridad existencial. Este derecho debe estar garantizado para que su ejercicio no sea ilusorio sino real. $(L S, 94)$

Dicha encíclica "ecológica" busca aplicaciones concretas de la doctrina social de la Iglesia. Francisco hace de la tierra un objeto de preocupación y amor, proponiendo un ecologismo que respete al pobre, lo dignifique y le proponga el ideal de una «civilización del amor»", (como quiso Pablo VI). En la exhortación apostólica Amoris laetitia $(A L)$ el Papa insiste, además, en unir doctrina y praxis sociales ( $A L, 1$ y 3$)$.

\section{Cardenal y Francisco: ora, labora et collabora}

Buscando su segunda vocación, la de un contemplativo religioso, el poeta Ernesto Cardenal encuentra en su camino al otro poeta, Thomas Merton, y con él, como maestro de novicios, vive el tiempo de noviciado en la abadía trapense de Gethsemani, Kentucky. Más tarde recuerda las imágenes que le han marcado de por vida. Los monjes trapenses pasan sus noches en vela rezando y se parecen a "las lámparas de las vírgenes prudentes esperando / al esposo en la noche de los Estados Unidos" (Cardenal, 1994: 102). La vía contemplativa iniciada en la Trapa tiene para Cardenal su continuación cuando funda la comuna en Solentiname al reunir "partículas conscientes de un solo organismo" (Cardenal, 2012a: 82), el de la Iglesia. Pone en marcha el proyecto de

\footnotetext{
${ }^{1}$ Según el citado aquí San León Magno, "Si la fe no es una, no es fe".
} 
San Benito de ora et labora, al practicar el amor fraterno y la solidaridad con los pobres. De ahí dice sentir la fuerza de la Iglesia:

No olvidemos que San Benito fue capaz de transformar a toda Europa. Si hubiera estado aislado, como ahora algunos quieren estarlo, no hubiese sido proclamado patrono de ese continente. (Flores, 1975: 180)

Sugiere que es necesario conservar el alma contemplativa de la Iglesia que debería saber orar por el hermano sufriente. De lo contrario, si no tiene lugar el aggiornamento en los monasterios contemplativos, obtendremos una caricatura de la vida monacal:

Hay conventos de monjitas, que como de algo tienen que vivir, viven de la venta de reliquias

un hilo de la sotana de San Juan Bosco, un polvito de huesito de San Caralampio.

(Cardenal, 2012a: 309)

La experiencia de la comuna de Solentiname es bien conocida a través de los sermones compartidos de El Evangelio en Solentiname (1975, reed. 2006) y las memorias de Las insulas extrañas. Cardenal recapitula en estas obras su idea de la contemplación y explica su eclesiología. Intuye que Solentiname fue un experimento de ser individuo solitario pero buscando compañía: “¿Cuáles islas? Las islas somos todos. // También Solentiname" (Cardenal, 2012a: 348). La contemplación y el trabajo con los jóvenes le hace más radical y, en consecuencia, en Solentiname crece la conciencia de la revolución, por lo cual, más tarde, algunos de sus miembros toman las armas y se sublevan contra el somocismo. El mismo Cardenal cree en el futuro de la Iglesia católica en América Latina, unida ideológicamente con el marxismo (cfr. Dalton, 1974: 31).

El mencionado Thomas Merton le enseñó a Cardenal que el amor es lo básico. La mejor tríada de los medios para cultivarlo es: la pobreza, la muerte y la comunidad (Flores, 1975: 176). De ahí la importancia de la noción de 'comunidad' en toda la producción de este 
poeta nicaragüense. ${ }^{2}$ Merton mostró dos caras de la Iglesia: la práctica (labora) y la contemplativa (ora), entre las cuales no habría, según él, separación. Ernesto trata de no repetir los errores de varias organizaciones eclesiales ricas como lo son ciertas órdenes llamadas "mendicantes". Explica la principal diferencia entre su propio modelo de la Iglesia y el tradicional, haciendo referencia a su comunidad isleña:

Esto no es un monasterio. He querido fundar, más bien, una pequeña comuna en Solentiname. Y las diferencias que hay entre esto y la trapa son todas las que puede haber entre una pequeña comuna sin reglas ni estatutos y un monasterio con tantos reglamentos y tradiciones, etc., como ésos. (Flores, 1975: 181)

Además, continúa aclarando la peculiaridad de su fundación:

Era un grupito, no fue ni marxista ni cristiano, no fue nada, teníamos una orientación marxista y cristiana, revolucionaria, pero algo muy pequeño, insignificante que luego se hizo un mito. [...] la revolución es lo que nos ha hecho humanos, toda la humanidad ha vivido de revolución en revolución [...] revolución es amor. (González Harbour, 2015)

Como declara él mismo, la sencillez, la pobreza y el compartir (es decir, collaborare), se convirtieron en una regla en su pequeña comuna. El momento central en ella siempre fue el día de domingo, con la misa comentada y el sermón en forma de coloquio abierto:

[...] las misas eran todos sentados en una mesa, alrededor de la mesa. Ernesto Cardenal a la cabeza, ¿eh?, con la liturgia de la palabra que leía; las lecturas, hacían las lecturas, las comentábamos, y pasábamos a la eucaristía, que lo...era una experiencia realmente de vivir lo sagrado del rito. Vivíamos eso, eso era muy bello, las misas eran como ajenas totalmente a las misas obligatorias del colegio, ajenas a los beatos [...]. (Dueñas García de Polavieja, 2012a: 9)

A través de este tipo de encuentros, se promovía un modelo de Iglesia no clerical y libre de una solemnidad ostentosa. Prevalecía la

\footnotetext{
${ }^{2}$ Acerca de este tema remitimos a Drozdowicz (2015).
} 
fraternidad y no el rito: "[...] el asunto es que era una sola familia... me atrevo a decir que era como una sola familia toda la comunidad de Solentiname, porque era muy unida, muy unida" (Dueñas García de Polavieja (2012a: 10). Con este fin propuesto y para dar preferencia a las relaciones interpersonales, el poeta-sacerdote hizo suprimir las procesiones, muchas devociones a la Virgen, hizo disminuir el número de ornamentos, ritos excesivos (Cardenal, 2002: 228). En fin, en Solentiname la Iglesia (y el cristianismo) se presenta como simple, latinoamericanista, con la forma de vestir y ser campesina, ya que se usaba como hábito una "cotona blanca, blue jeans, sandalias", para imitar mejor a los pobres del lugar y atraerlos (López-Baralt, 2012a: 14).

También por el personaje de Thomas Merton, Cardenal se acerca al Papa Francisco. El Pontífice reconoció a este contemplativo trapense al referirse a él durante su visita a los Estados Unidos en verano de 2016. El poeta le atribuye a Francisco el tener un instinto pluralista, ya que Merton, como reformador de la Iglesia preconciliar, buscaba atar los cabos sueltos entre las religiones. He aquí las palabras que expresan la similitud del pensamiento entre el argentino y el nicaragüense:

[...] Thomas Merton fue el que me dio la formación espiritual, fue mi padre espiritual y ha sido una de las personas más importantes de la Iglesia de hoy. Me pareció muy bueno que el Papa Francisco se lo mencionara a los norteamericanos en el Congreso de los Estados Unidos. Él fue uno de los reformadores de la Iglesia en sus escritos como el Papa Francisco. Y una de las cosas en los que más insistió Merton fue en un pluralismo religioso [...]. El pluralismo religioso es que todas las religiones nos llevan a Dios y que todas las religiones son verdaderas. [...]. Pero la máxima verdad es que ninguna religión nos debe dividir. Y esto es lo que también nos enseña el Papa Francisco. ("Francisco es mejor...", 2016)

Justificando su teología, Cardenal se vale de ciertos fragmentos de los Padres y Doctores de la Iglesia al explicar las ansias que siente ahora el pueblo en varios países del mundo: 
L Iglesia decía: Recuerda que no eres propietario, sólo administrador de los bienes que son de todos. La Iglesia predicaba el comunismo. A eso se debe que surgiera el comunismo en Occidente -aun cuando fue al margen del cristianismo. Comunistas fueron los Padres de la Iglesia. (Cardenal, 2002: 319)

Y entre comunistas hay que contar a San Gregorio de Nisa, San Agustín, San Basilio, San Clemente Romano, Tertuliano. También toda la Biblia "está siempre hablando de la lucha de clases" (Cardenal, 2002: 320). Lo mismo parece intuir el Papa, al afirmar en una entrevista reciente para el diario La Repubblica:

Son los comunistas los que piensan como los cristianos. Cristo ha hablado de una sociedad donde los pobres, los débiles y los excluidos sean quienes decidan. No los demagogos, los barrabás, sino el pueblo, los pobres, que tengan fe en Dios o no, pero son ellos a quienes tenemos que ayudar a obtener la igualdad y la libertad. (El Confidencial, 2016)

Indudablemente, tanto para Francisco como para Cardenal, la Iglesia necesita ser depurada de los malos ministros, de la ostentación, de la elección de una vida cómoda. En una de las entrevistas dice el poeta: "Jesucristo [...] echó a latigazos a los mercaderes que habían hecho del templo, de la casa de Dios, un lugar de especulación" (Dalton, 1974: 23). Esta situación muestra también la osadía de un renovador religioso que muestra el furor Domini sagrado para establecer nuevos paradigmas. De ahí que el padre Ernesto diga que "Jesús, que no observó las leyes de los judíos, rompió con el Sábado, puso en peligro el Templo, se juntó con los publicanos y pecadores, y habló de poseer algo divino, sólo propio de [Y]avé" (Dapaz Strout, 1975: 110).

Cardenal critica el anticlericalismo, atacando la situación religiosa en Colombia, donde (en Antioquia) había completado sus estudios teológicos. A base de sus experiencias transcribió con amargura las palabras de Fernando González: "En Colombia todos somos seminaristas" (Cardenal, 2002: 16). Y también:

Colombia es el país más católico de América Latina, y Antioquia, donde nosotros estábamos, es el departamento más católico de Colombia [...]. 
Y allí [en Antioquia] se ha visto a un cura cargando una gran cruz en la que clava los billetes que le dan hasta que la cruz queda toda cubierta de billetes. [...]. Y actualmente con el narcotráfico, los llamados sicarios, los niños organizados para asesinar, son devotos de la Virgen de la Sabaneta, su patrona, y van a ella a rezarle (como los toreros a la Macarena antes de la corrida) para que no les falle la puñalada o el tiro. ¡Cuánta religiosidad ha habido en Antioquia, Ave María! (Cardenal, 2002: 16-17)

Para Cardenal, el clericalismo es una postura equivocada, porque Jesús pertenecía a la casta sacerdotal y ninguno de sus apóstoles fue del estado clerical. Al contrario, los sacerdotes, fariseos y expertos en la ley religiosa son el blanco más frecuente de sus ataques, incluso airados. El clericalismo (sacerdotalismo) es responsable de la popularización del modelo equivocado del sacerdocio, concebido como el ascenso social (Cardenal, 2002: 18, 63).

Ampliamente comentado en la poesía de Cardenal es el mal de la riqueza de la Iglesia, observada en el modo de vivir de sus ministros, curas, obispos, nuncios y cardenales. Es recordado el lujo de la nunciatura en Bogotá, con sus carísimos cristales de vidrios de sus ventanas repetidamente rotas a propósito por los jóvenes manifestantes. Después, dentro del palacio, "se veía todo el lujo insensato" (ibidem). En Cántico cósmico se retoman las críticas del esplendor de la Iglesia:

Templo de Dios.

Templo de Dios.

Templo de Dios.

Templo de Dios por donaciones de cueva de ladrones.

"Los ricos que pasan en sus carros que echan polvo"

(Cardenal, 2012a: 205)

El acercamiento de la Iglesia a los centros de poder es algo nefasto. Mientras los prelados frecuentan las casas de los gobernantes, Jesús está en otra parte: "Xto. presente en las celdas de las cárceles / y no en los palacios episcopales" (Cardenal, 2012a: 272). Presionados por los dictadores y sus gobiernos, los obispos desvían la atención del pueblo de los temas verdaderamente importantes ("peligrosos"). 
Debido a eso un obispo canario "bajo Somoza III inauguró / su episcopado con importantísima pastoral sobre / aquel gravísimo mal: / la minifalda" (ibidem). Citado, en La revolución perdida, José Coronel Urtecho resumió sarcásticamente el estado de estas cosas: "El Vaticano se acostó con la Agencia Central de Inteligencia" (Cardenal, 2004: 319), convirtiéndose la Iglesia en una institución "zombificada" (Cardenal, 2012a: 195). En "Cantiga 24" los obispos son "herejes" porque desconocen los problemas de sus pueblos, formando una casta de privilegiados (Cardenal, 2012a: 193). También el Papa Francisco critica este problema, condenando las alianzas non sanctas con las dictaduras de antaño y con el capital. Se atreve a echarle la culpa a los prelados y, en Evangelii gaudium, clarifica el sentido de la responsabilidad global de los jerarcas:

No nos hagamos los distraídos. Hay mucho de complicidad. ¡La pregunta es para todos! En nuestras ciudades está instalado este crimen mafioso $\mathrm{y}$ aberrante, y muchos tienen las manos preñadas de sangre debido a la complicidad cómoda y muda. $(E G, 211)$

En la actualidad la Iglesia, por cierto semper reformanda, exige una reforma urgente y con miras al orden mundial:

Pero en el Vaticano, vino viejo en odres viejos, en odres tan viejos como la palabra odres.

Nos acusan por nuestros augurios triunfalistas.

¿Pero alguna vez ha habido un profeta conservador

o reaccionario?

(Cardenal, 2012a: 155)

Como hemos observado, Cardenal considera que el Vaticano, por falta de impulso, no se atrevía a grandes cambios y solo habría que esperar al otro Papa, el argentino, para que las cosas se movieran de su lugar, si fuera necesario.

\section{Conclusión}

La obra del poeta-profeta Cardenal propone dejar las diputas estériles entre teólogos y volver a los orígenes, "cuando el hombre vivía una 
vida simple, armónica y regida por las leyes divinas" (Oviedo, 2005: 126). Del otro lado de la trinchera (que, con el Papa Francisco, parece más una mesa redonda) tenemos al Papa que sugiere volver al estado de inocencia de la Iglesia. Dejando al lado sus "lentes dogmáticas" (Oviedo, 2005: 127), tanto el Pontífice como su oveja son hombres de futuro. Y, aunque aún no se han encontrado en persona, están ya sentadas las bases para hacer las paces con la Teología de la Liberación. Se sabe que entre el padre Ernesto y su Pastor ha surgido la simpatía. Y en griego sympátheia significa simplemente 'sentir igual que otro'.

\section{Bibliografía}

BARGIELSKA, J. (2016), "Kurier z perłą", Tygodnik Powszechny, 32, pp. 17-18.

BARRERA PARRILLA, B. (2008), "La poesía de Centroamérica: vanguardia y postvanguardia", en: Barrera, T. (coord.), Historia de la literatura hispanoamericana. T. III. Siglo XX, Cátedra, Madrid, pp. 559-577.

CARDENAL, E. (1994), Poesía, Libresa, Quito, [on-line] https://books.google.es/books?isbn=9978802517, 5.09.2016.

CARDENAL, E. (2002), Las ínsulas extrañas. Memorias 2, Editorial Trotta, Madrid.

CARDENAL, E. (2004), La revolución perdida. Memorias 3, Editorial Trotta, Madrid.

CARDENAL, E. (2012a), Cántico cósmico, $4^{\mathrm{a}}$ ed. corregida, Editorial Trotta, Madrid.

CARDENAL, E. (2012b), Que voy de vuelo. Antología mística, Anamá Ediciones, Managua.

CARDENAL, E. (2015), “La revolución del Papa Francisco”. Huffington Post, 30.01.2015, Madrid, [on-line] http://www.huffingtonpost.es/rev-ernesto-cardenal/francisco-un-nuevo-Papa_b_6569358.html, 9.09.2016.

DAPAZ STROUT, L. (1975), "Nuevos cantos de vida y esperanza. Los salmos de Cardenal y la nueva ética", en: Promis Ojeda, J. (et al.), Ernesto Cardenal. Poeta de la liberación latinoamericana, Fernando García Cambeiro, Buenos Aires, pp. 107-131. 
DALTON, R. (1974), “Apuntes de dos encuentros con Ernesto Cardenal”, en: Cardenal, E., Castro, F., Cristianismo y Revolución, Editorial Quetzal, Buenos Aires, pp. 9-31.

DROZDOWICZ, M. (2015), En busca del Reino de Dios. La dimensión comunitaria de la obra de Ernesto Cardenal, Ostravská univerzita-Filozofická fakulta, Ostrava.

DUEÑAS GARCÍA DE POLAVIEJA, I. (2012), "Historia oral de la resistencia nicaragüense al somocismo: el proyecto de Ernesto Cardenal en Solentiname como paradigma de la liberación", Naveg@mérica. Revista Electrónica de la Asociación Española de Americanistas, 8, Murcia, pp. 1-15, [on-line] https://revistas.um.es/navegamerica/article/ view/150111, 1.08.2016.

DUSSEL, E. (1983), Historia general de la Iglesia en América Latina, tomo I/1. Introducción general, CEHILA Ediciones-Sígueme, Salamanca, [on-line] biblioteca.clacso.edu.ar/clacso/otros/20120215104509/iglesia2.pdf, 25.09.2016.

"El Papa asegura que «son los comunistas los que piensan como los cristianos»" (2016), El Confidencial, 11.11.2016, Pozuelo de Alarcón [Madrid], [on-line] http://www.elconfidencial.com/sociedad/2016-11-11/papa-francisco-comunistas-cristianos 1288123/, 11.11.2016.

"Ernesto Cardenal: «Francisco es un milagro, un Papa que ha renunciado a vivir como Papa»" (2014), Periodista Digital, 26.06, Madrid, [on-line] http://www.periodistadigital.com/religion/america/2014/06/26/ernesto-cardenal-francisco-es-un-milagro-un-Papa-que-ha-renunciado-a-vivir-como-Papa-iglesia-religion-poeta-sacerdote-nicaraguense-leccion-jesusmensaje.shtml, 9.09.2016.

FLORES, F.J. (1975), “Comunismo o Reino de Dios. Una aproximación a la experiencia religiosa de Ernesto Cardenal”, en: Promis Ojeda, J. et al., Ernesto Cardenal. Poeta de la liberación latinoamericana, Fernando García Cambeiro, Buenos Aires, pp. 159-190.

FRANCISCO (2013a), Evangelii gaudium, Tipografía Vaticana, Vaticano, [on-line] https://w2.vatican.va/content/dam/francesco/pdf/apost_exhortations/documents/Papa-francesco_esortazione-ap_20131124_evangelii-gaudium_sp.pdf, 1.08.2016. 
FRANCISCO (2013b), Lumen fidei. Tipografía Vaticana, Vaticano, [on-line] http://w2.vatican.va/content/dam/francesco/pdf/encyclicals/documents/ Papa-francesco_20130629_enciclica-lumen-fidei_sp.pdf, 1.08.2016.

FRANCISCO (2015), Laudato sì, Tipografía Vaticana, Vaticano, [on-line] http://w2.vatican.va/content/dam/francesco/pdf/encyclicals/documents/ Papa-francesco_20150524_enciclica-laudato-si_sp.pdf, 1.08.2016.

FRANCISCO (2016), Amoris laetitia, Tipografía Vaticana, Vaticano, [on-line] http://w2.vatican.va/content/dam/francesco/pdf/apost_exhortations/ documents/Papa-francesco_esortazione-ap_20160319_amoris-laetitia_ sp.pdf, 1.08.2016.

"Francisco es mejor de como podríamos haberlo soñado. Entrevista con Ernesto Cardenal" (2016), El Pais, 12.02, Madrid, [on-line] http://internacional.elpais.com/internacional/2016/02/11/actualidad/1455197417_056596. html, 9.09.2016.

GONZÁlEZ HARBOUR, B. (2015), "Ernesto Cardenal: «El Papa Francisco hace la revolución». Entrevista”, El País-Cultura, 02.06.2015, Madrid, [on-line] http://cultura.elpais.com/cultura/2015/06/02/babelia/1433240553_228692.html, 9.09.2016.

La Biblia Latinoamericana (1989), edición pastoral, texto íntegro traducido del hebreo y del griego, $30^{\mathrm{a}}$ ed. San Pablo-Editorial Verbo Divino, Madrid-Estella.

LÓPEZ BARALT, L. (2012), “Introducción”, en: Cardenal, E., Que voy de vuelo. Antología mística, Anamá Ediciones, Managua, pp. 11-41.

NAPIÓRKOWSKI, A. (2011), Kościót dla człowieka. Błogosławionego Jana Pawła Wielkiego mistyka eklezji, Uniwersytet Papieski Jana Pawła II, Kraków.

OVIEDO, J.M. (2005), Historia de la literatura hispanoamericana. 4. De Borges al presente, Alianza Universidad, Madrid.

SPORNIAK, A. (2016), "Franciszek do biskupów", Tygodnik Powszechny, 32, p. 23.

VARELA-IBARRA, J. (1974), "La poesía de Ernesto Cardenal”, Mester, IV. 2, Los Ángeles, pp. 137-140. 